\title{
Filosofia Africana do Encantamento tecida por mulheres negras: poéticas de re-existências para descolonização do conhecimento
}

\author{
Filosofía africana del encantamiento tejida por \\ mujeres negras: re-existencias poéticas para \\ descolonizar el conocimiento
}

AdILBÊNIA FREIRE MACHADODa

\section{Resumo}

Este artigo tem o objetivo de dialogar com vozes femininas de África e da Diáspora Africana tecendo re-existências desde a Filosofia Africana do Encantamento, refletindo possibilidades plurais e ancestrais para descolonização do conhecimento e promoção de uma educação antirracista. Nesse sentido, caminharemos com a pedagogia da ancestralidade que nos exige modos outros de (re)pensar, refletir, (re)criar, e (re)posicionar-se, oriundos de práticas inclusivas e tecidas por nossos corpos, pelas memórias, conhecimentos ancestrais, saberes e histórias de nossos povos, partindo da ligação ancestral entre corpo, espiritualidade e natureza; e a metodologia dos Odus, que também é uma teoria, implicada em compreender nossas origens, por meio de processos de desconstruções, transições, transformações, encantamento, espaço, tempo e natureza como modos plurais de ser/ pensar/existir em busca de contribuir com a descolonização do conhecimento, de nossos corpos e sentidos. Assim, essa teia será construída em diálogo com o ser-tão que há em nós, com a escuta sensível e a ética do cuidado, considerando que são conceitos delineados pela ancestralidade e pelo encantamento. A filosofia africana contemporânea nasce do encantamento, portanto, é traçada pela ancestralidade, e assim apresenta-se como gestada desde a cabaça ancestral bordada pelos saberes ancestrais femininos. Esses saberes (a)bordam nossas

\footnotetext{
a Universidade da Integração Internacional da Lusofonia Afro-Brasileira (UNILAB), Fortaleza, CE, Brasil. Doutora em Educação, e-mail: adilmachado@yahoo.com.br
} 
escrevivências, dando sentido às re-existências cotidianas. São saberes experienciados por corpos carregados de sentidos, corpos sagrados, ancestrais. Desse modo, falamos desde cosmopercepções delineadas por cosmossensações de um corpo vivo, que aprende e ensina continuamente. Pois compreendemos que o conhecimento é movimento! O movimento é que proporciona a vida! De modo que os femininos são águas em movimentos ancestrais que permitem a existência do hoje e do amanhã.

Palavras-chave: Ancestralidade. Metodologia dos Odus. Saberes Ancestrais Femininos.

\section{Resumen}

Este artículo tiene como objetivo dialogar con las voces femeninas de África y la diáspora africana tejiendo re-existencias desde la Filosofía africana del encantamiento, reflejando las posibilidades plurales y ancestrales de descolonizar el conocimiento y promover la educación antirracista. En este sentido, caminaremos con la pedagogía de la ascendencia que requiere otras formas de (re) pensar, reflexionar, (re) crear y (re) posicionar desde prácticas inclusivas y tejidas por nuestros cuerpos, por memorias, saberes ancestrales, saberes e historias de nuestros pueblos, a partir de la conexión ancestral entre cuerpo, espiritualidad y naturaleza; y la metodología Odus, que también es una teoría, involucrada en la comprensión de nuestros orígenes, a través de procesos de deconstrucción, transiciones, transformaciones, encantamiento, espacio, tiempo y naturaleza como formas plurales de ser / pensar / existir en busca de contribuir con la descolonización de conocimiento, de nuestros cuerpos y sentidos. Así, esta web se construirá en diálogo con el ser que está en nosotros, con la escucha sensible y la ética del cuidado, considerando que son conceptos trazados por la ascendencia y el encantamiento. La filosofía africana contemporánea nace del encantamiento, por lo tanto, se rastrea por la ascendencia, y así se presenta como gestada de la calabaza ancestral bordada por el conocimiento ancestral femenino. Estos conocimientos (a) bordan nuestros registros, dando sentido a las reexistencias diarias. Son conocimientos experimentados por cuerpos cargados de sentidos, cuerpos sagrados, ancestros. De esta manera, hablamos desde las cosmopercepciones perfiladas por las cosmosensaciones de un cuerpo vivo, que aprende y enseña continuamente. iPorque entendemos que el conocimiento es movimiento! iEl movimiento es lo que da vida! De modo que lo femenino son aguas en movimientos ancestrales que permiten la existencia de hoy y mañana. i

Palabras-clave: Ancestralidad. Metodología Odus. Conocimiento ancestral femenino. 


\section{Tecendo fios iniciais}

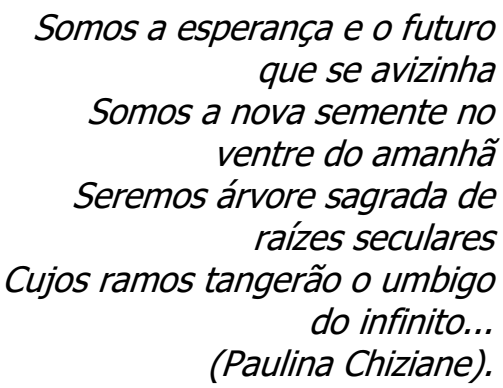

Esse artigo/ensaio tem o intuito de tecer perspectivas plurais e ancestrais de "libertação", pertencimento, emancipação, descolonização, contribuindo para a promoção de uma educação antirracista, amorosa, perpassada por implicaAÇÕES oriundas do transforAMAR, das poéticas de encantamento. São tessituras em construção/movimento, para serem lidas, significadas, ressignificadas e até reescritas, desconstruídas... Afinal, escrever é gritar o silêncio engasgado, é contar histórias, as nossas histórias, onde somos agentes de/da e para a transformAÇÃO, é tecelar saberes e fazeres, pois, como nos ensina Aline Matos da Rocha: “as tecelãs em um contínuo movimento de vai e vem produzidos por seus pés que sobem e descem sobre os pedais do tear, possuem o poder de (des)fazer, fiar e construir os mais diversos tipos de tecido" (2020, Le Monde Diplomatique, on-line). Nesse sentido, nos propomos a teiar/crochetear/tecer diálogos desde/com vozes femininas oriundas das cabaças das existências africanas em África e na sua diáspora.

Assim, pedimos licença à ancestralidade para que possamos fiar diálogos construtivos contribuindo com a emancipação humana, com a descolonização do conhecimento. Conversas tecidas por saberes e epistemologias antirracistas e antissexistas, tendo as filosofias africanas como novelos dessas construções, tecendo mundos encantados, implicados com o bem viver.

A emancipação propõe libertAÇÃO, transformAÇÃO social, política, cultural e a educação afroancestral encantada é um caminho para essa realização, pois implicase com a desconstrução de currículos monorreferenciados, eurocentrados, propondo perspectivas plurais, descolonizadas, criação de metodologias e didáticas diversas, tecidas em nós, por nós, pois que a descolonização do conhecimento emancipa por ser tricotada por conhecimentos/saberes/viveres plurais, ancestrais e encantados, posto que a potencialização da vida é seu propósito maior. O projeto de emancipação 
e libertação do povo africano e afro-diaspórico é para toda a humanidade. As filosofias africanas apresentam perspectivas críticas de ressignificações da própria filosofia, anunciando modos outros de pensar e construir epistemologias, modos outros de ser e estar no mundo, modos outros de filosofar. Cabe a pergunta: por que anunciar filosofias anteriores à filosofia ocidental? Esse é o novelo da descolonização.

Assim, nessas águas de libertação e emancipação antirracista e antissexista, ancestral e encantada, faço-lhes dois convites para que possamos realizar movimentos que fiarão todo o texto: Movimento Sankofa e Movimento Escrevivência.

\title{
Movimento Sankofa e Movimento Escrevivência: na encruzilhada com os Odus
}

\author{
lembre-se do corpo \\ da sua comunidade \\ espire $o$ ar do povo \\ que costurou seus pontos \\ é você quem se tornou você \\ mas as pessoas do passado \\ são parte do seu tecido \\ - honre suas raízes \\ (rupi kaur).
}

O movimento Sankofa nos enraíza, fortalecendo nosso presente assentado em um passado que permite outros futuros, não podemos pensar o futuro sem estarmos enraizadas com nossos antepassados, é como o provérbio nos ensina: "quando não souberes para onde ir, olhas para trás e saibas de onde tu vens". Sankofa é o movimento da ancestralidade, nos ensina de onde a gente vem, enraizando, para que possamos saber para onde irmos, para termos caminhos a seguir e não ficarmos perdidas, sem direção, e assim, sem sentidos. Sankofa enraíza. Enraizamento é ancestral.

Esse movimento de caminhar para frente tecidas pela ancestralidade, por nossas raízes, é próprio do Odu de Origem, pois compreendemos a importância infinita de conhecermos nossas origens e isso se dá desde "memórias, saberes, fazeres e dizeres” (MEIJER, 2012, p. 34), pois “as raízes da [cosmopercepção] africana no Brasil possuem algumas características curiosas. Uma delas é a constatação, óbvia, por sinal, de que são diaspóricas, ou seja, "desterritorializaram-se” da África e migraram 
firmando-se em terras brasileiras" (Idem). Desse modo, a diáspora "gerou, entre outros fenômenos, a oportunidade da raiz africana atravessar o atlântico a nado (o “desterritório”) e enraizar-se em várias partes do mundo, ganhando, em cada lugar, propriedades locais e específicas, mas sempre preservando elementos da África" (Idem). Portanto, perspectivas afrorreferenciadas, ou seja, ancestrais e encantadas, implicam-se em movimentos de enraizamento: “enraizar-se é deixar-se atravessar pelos corpos-raízes da [cosmopercepção] africana no Brasil [...]. A raiz tem movimento [...]. O enraizamento é flexível, descontínuo e histórico e acontece à medida que a vida vai sendo devorada pelo tempo", como nos ensina Rebeca de Alcântara Silva e Meijer (2012, p. 34). Raízes/origens nos remetem a movimento e profundidade, passado e futuro, em que o presente se pauta pelo adubo do passado, ou seja, da ancestralidade que é passado, presente e futuro... É preciso aguar nosso ser/fazer, pois a ancestralidade vive, não apenas nos acolhe, como também nos habita... Somos seres ancestrais!

O conhecimento desde perspectivas afrorreferenciadas, desde cosmopercepções africanas, é tecido pelo conhecer/aprender/ensinar por meio das experiências, das vivências, pois o conhecimento real, que pode ser efêmero, tem origem em nós, em nosso lugar de pertencimento, nosso chão, nossas raízes, nossas culturas e saberes, nossas tradições, nossas intimidades, nossos corações. É preciso ouvir nossa intimidade, educar o olhar, os sentidos, educar para a sensibilidade, para perceber que somos parte do todo e o todo é parte de nós, promovendo exercícios de potencialização das nossas capacidades de sentir, de ter a emoção como base, como sustentáculo, pois "em formação é preciso entender que a emoção coloca o sujeito em movimento e impulsiona a ação" (MACEDO, 2010, p. 129). O enraizamento é movimento. MovimentAÇÃO. Nesse sentido, é necessário a reescrita de si, da nossa história, pois "a história é a memória dos povos, [...] esse retorno a si mesmo pode, aliás, revestir-se do valor de uma catarse libertadora" (KI-ZERBO, 2010, XXXIII). Desse modo, nossas raízes, nossa história, são adubadas pelas escritas de si, por nossas escrevivências, escritas como catarse libertadora, de emancipação e encantadas.

Os saberes afrorreferenciados, as filosofias africanas, são tecidas pelas escrevivências, pois são filosofias da práxis, portanto, nossas reflexões, debates, críticas, com-versas, são delineadas pelas práxis do nosso ser/estar no mundo, práticas vivas 
e implicadas em transformar o mundo, afinal, outros mundos são possíveis, mundos tecidos por poéticas de encantamento que bordam desejo-ação de bem viver!

Escrevivência é conceito - práxis que fala (ação) de nossas histórias desde nossos modos próprios de dizer, contar, escrever, pensar, refletir, educar, ensinar, filosofar... fala de nossos sentidos e sentimentos, de nossas vivências — experiências, nossos saberes, nossas dores e alegrias, nossas danças e encantos. É estético, filosófico, histórico, geográfico, literário, metodológico... É plural, feminino, interseccional, tecido pela ancestralidade, pela oralidade, pela atemporalidade, pela escuta sensível (MACHADO, 2019). Conceição Evaristo, sábia que gerou e pariu esse conceito práxis, metodologia, diz:

Escrevivência, em sua concepção inicial, se realiza como um ato de escrita das mulheres negras, como uma ação que pretende borrar, desfazer uma imagem do passado, em que o corpo-voz de mulheres negras escravizadas tinha sua potência de emissão também sob o controle dos escravocratas, homens, mulheres e até crianças. E se ontem nem a voz pertencia às mulheres escravizadas, hoje a letra, a escrita, nos pertencem também. Pertencem, pois nos apropriamos desses signos gráficos, do valor da escrita, sem esquecer a pujança da oralidade de nossas e de nossos ancestrais. Potência de voz, de criação, de engenhosidade que a casa-grande soube escravizar para o deleite de seus filhos. E se a voz de nossas ancestrais tinha rumos e funções demarcadas pela casa-grande, a nossa escrita não. Por isso, afirmo: "a nossa escrevivência não é para adormecer os da casa-grande, e sim acordá-los de seus sonos injustos". Nossa escrevivência traz a experiência, a vivência de nossa condição de pessoa brasileira de origem africana, uma nacionalidade hifenizada, na qual me coloco e me pronuncio para afirmar a minha origem de povos africanos e celebrar a minha ancestralidade e me conectar tanto com os povos africanos, como com a diáspora africana (EVARISTO, 2020, p. 30-31, grifos meus).

Escrevivência é um conceito costurado, desenhado, bordado, crocheteado, criado desde a ética da existência, da resistência, da re-existência, de libertação, emancipação, é ancestral, ética do cuidado, poética de encantamento. É escuta sensível, ou seja, abertura para conhecer, sentir, perceber as outras pessoas de modo integral, inclusive as diversas pessoas que há em nós, delineando uma escuta afetiva e efetiva, por isso é também ancestral, é escuta da nossa intimidade, de nossos corações, de nossa ancestralidade. Ouvir/sentir nossa intimidade é o feminino tecendo poéticas de potencialização da vida. Escrevivências são estéticas de sentidos implicadas na descolonização, na potencialização dos nossos saberes, descolonização dos sentidos, de nossos corpos e, assim, do próprio conhecimento, pois este é tecido por nossos corpos-territórios escreviventes. Conceição Evaristo, mulher encantada, nos $\operatorname{diz}($ ensinando): 
tudo que escrevo, [...] toda minha criação surge marcada pela minha condição de mulher negra na sociedade brasileira. As escolhas temáticas, o vocabulário, as personagens, os modos de construção das mesmas, o enredo, nada nasce imune ao que sou, às minhas experiências, à minha vivência. Escrevo uma vivência, que pode ser ou não, a real, a vivida por mim, mas que pode se con(fundir) com a minha (2017, p. 07, grifo meu).

Contar nossas histórias é reconhecer e valorizar nossas origens, é pertencer. O saber ancestral é experiencial! Nossas ramificações são tecidas pela ancestralidade, germinando e sendo germinadas pelo encantamento! Assim, o Odu de Origem nos ensina a importância de sabermos de onde partimos, saber onde estão nossas raízes. Saber nossas origens, conhecê-las, re-conhecê-las não é uma escolha arbitrária, além de ser coletiva, fruto de uma cultura, de uma tradição, de um chão, de uma ancestralidade que é fonte de pertencimento e que tece esse chão/lugar, espaçoterritório regido pelo tempo da natureza, tempo do aprender. É o nosso ser-tão, ou seja, sentidos, afetos, desejos, buscas, sonhos, energias, conhecimentos, saberes que bordam nosso existir, nossas escrevivências, compreendendo o conhecimento como gestado e parido por nossas experiências, trajetórias, histórias, vivências, assim, é necessário mergulhar em nossos corações, nossas emoções, nosso próprio corpo. Sertão é nossa intimidade, é o bordado que a ancestralidade faz em nós, em nosso corpo, por isso, nossos corpos são produtores de sentidos, de conhecimentos, implica-se em sermos em toda nossa imensidão, sem silenciamentos e padrões que nos diminuem, adoecem, colonizam.

O ser-tão, munido pela escuta sensível, nos leva a compreensão de que só existimos em relação com a natureza. A natureza é o ser-tão que há em nós. Intimidade com a espiritualidade que nos habita, com nossa ancestralidade. É a liberdade vivida, pois “a liberdade não se expressa. Vive-se” (CHIZIANE, 2013, p. 29). O povo negro luta diariamente por liberdade, pelo próprio viver, bem-viver.

Portanto, ouvir o ser-tão que nos habita, implica enraizamento, é caminhar pelo Odu de Natureza, pois é a natureza que nos permite viver, sem ela não somos, não criamos, não respiramos, ela é a própria vida, é movimento da existência, é ancestralidade que habita em nós e que nos permite ser, como Makota Valdina Pinto ensina:

Ancestralidade pra mim é tudo o que veio antes de mim. Então, a natureza é a minha ancestralidade. [...] E a natureza não foi o [ser humano] que fez, o [ser humano] veio 
depois, veio depois que toda a natureza foi criada pra dar boa intenção de vida pro [ser humano]. Então, a minha ancestralidade é toda a natureza que foi criada pela primeira semente viva que iniciou esse mundo. [...] Minha ancestralidade é a natureza (PINTO, 2017, fonte oral, grifos meus).

A natureza é fonte para nosso caminhar, nosso viver, bem viver. $\mathrm{Na}$ relação íntima com a natureza podemos "aprender/partilhar/ensinar através de experiências condizentes com as referências de matriz africana e as expressões da cultura na diáspora" (ALVES, 2015, p. 38). Desse modo, possibilita-se "proposta[s] educativa[s] que seja[m] transmitida[s] pelo corpo[s], pela ancestralidade, pela[s] cultura[s], pela[s] estética[s] africana[s] e pela tradição oral" (ALVES, 2015, p. 38), pela oralitura própria do nosso ser/fazer. Pois, como nos ensina Leda Maria Martins:

a oralitura é do âmbito da performance, sua âncora; uma grafia, uma linguagem, seja ela desenhada na letra performática da palavra ou nos volejos do corpo. [...] A memória dos saberes inscreve-se, sem ilusórias hierarquias, tanto na letra caligrafada do papel, quanto no corpo em performance. Nessa perspectiva podemos pensar, afinal, que não existem culturas ágrafas, pois nem todas as sociedades confinam seus saberes apenas em livros, arquivos, museus e bibliotecas, mas resguardam, nutrem e veiculam seus repertórios em outros ambientes de memória, suas práticas formativas (MARTINS, 2013, p. 77).

Nossos corpos são fonte das escrituras ancestrais, tecendo memórias que diz quem somos e que marca nosso lugar enquanto agentes históricos. A natureza nos tece, nosso corpo é memória, e nesse processos de escuta sensível, de enraizamento, de ser-tão, de descolonização, conhecer outros referenciais, compreender nossas origens, ter sensibilidade para ouvir nossa intimidade e ser em nossa plenitude, nos implica em processos diversos de transição, desconstrução, transformação, encantamento...

O Odu de Transição nos ensina sobre os processos de movimentação e mudança, nos explica sobre as construções de conceitos, de epistemologias racistas, sexistas, apontando caminhos para desconstrução. Um exemplo: sabemos que a hegemonia-cultural euro-americana (branca, masculina e heteronormativa) criou conceitos/categorias para sustentarem sua sede de dominação e superioridade, categorias/conceitos perpassados de preconceitos, racistas, sexistas, etc, racializando, assim, o conhecimento, além de privilegiar o gênero masculino (OYEWÙMI, 2004). Em se falando desse privilégio do gênero masculino, é absolutamente fundante desconstruirmos a ideia de "homem" para dizer humanidade, pois "o uso do masculino genérico para designar humanidade reduz automaticamente a existência de mulheres à não existência” (KILOMBA, 2019, p. 108), reduzindo, assim, as mulheres 
negras a não existência da não existência, a negação da negação, o outro do outro, o não ser do não ser (CARNEIRO, 2005; ROCHA, 2014). A transição implica na conscientização, também, de que "A cultura de dominação necessariamente promove os vícios da mentira e da negação" (HOOKS, 2017, p. 44). Odu de Transição é movimento da compreensão de que "muitos séculos de colonização fez surgir a impressão de que a figura do colonizador correspondia a de um ser supremo e que, portanto, deveria servir como parâmetro para modelos civilizatórios nas colônias" (MEIJER, 2012, p. 42), portanto, é necessário movimentar-se para descobrirmos que muitos dos nossos saberes "estavam [e estão] encobertos pelo pó do colonialismo e do neocolonialismo" (Idem) e, assim, descolonizar, transformar. Tirar o pó é passar pela transição do não perceber, do não ter consciência para o conscientizar-se da necessidade de tirar a poeira deixada, imposta pelos colonizadores. Movimentar-se, pois que o movimento é fruto das nossas intenções, dos nossos desejos, dos sopros de vida cotidianos movidos por nossas escrevivências, por nossas andanças, pela busca de descolonização epistemológica e de nossos próprios sentidos. Já nos ensina Birago Diop (2005, p. 91): "Escucha antes a las cosas / que lo que dicen las palabras: / la voz del fuego, clamorosa, / la voz del agua, siempre clara. / Escucha cuando el viento sopla / lo que solloza lá maleza: / es el soplo de los [las] ancestros”.

O conhecimento livre e criativo é contínuo, por isso o movimento é sua condição, posto que nada na natureza está parado e não há como pensar, produzir, conhecer, ser desde perspectivas afrorreferenciadas sem que estejamos em relação com a natureza, pois é ela que "nos ajuda a ser o nosso verdadeiro ser” (SOMÉ, 2007, p. 20). Porquanto, é fundamental desenvolver, criar epistemologias que acompanhem o movimento próprio da existência, da realidade que vemos, sabendo-se que há diversos modos de se ler as coisas, o mundo (as coisas do mundo), não há uma verdade absoluta, há verdades possíveis, realidades possíveis e diferentes, somos diversas, plurais. O Odu de Transição diz sobre o desejo, a busca-ação "para derrubar os obstáculos ao saber. [...] se render ao maravilhamento de aprender e reaprender novas maneiras de conhecer que vão contra a corrente" (HOOKS, 2017, p. 63). Desaprender as mentiras que sustentam a falsa superioridade do pensamento ocidental. É fundante essa reconstrução, desconstruirmos para potencializar a existência, para transformar desde um processo inclusivo, comunitário, circular. É 
preciso descolonizar nossos currículos, nossas metodologias, o pensamento, os sentidos...

O Odu de Desconstrução nos ensina que é necessário pensar com os pés, pois eles estão sempre plantados no chão, é necessário trazer a cabeça para o chão, pois o chão é raiz, é a inversão de paradigmas. É mexer nas estruturas, questionar o que está sedimentado e dar sentido desde o contexto em que se está inserida. Esse Odu move os acontecimentos que formam e transformam. Não é desconstruir para construir novamente, é desconstruir para transformar, mudar! Eduardo Oliveira (apud MACHADO, 2014, p. 121) diz que “desconstrução rima com a criação, (...) leva à necessidade de continuar produzindo conhecimento, porque caso contrário posso só repetir conhecimento e repetir não é criar”. Entretanto, há momentos em que a repetição é importante, mas não podemos ficar sempre na repetição, assim, faz-se necessário a criação e para isso é fundante "desconstruir conceitos, metodologias, visões, olhares, imaginários. Desconstruir estruturas sociais, históricas, políticas. [...] não é destruir, destruir significa que você vai eliminar, desconstruir significa que você vai decompor para compor novamente" (Idem). É desaprender o colonial para aprender a raiz.

Os movimentos dos Odus implicam-se com o aprender, desaprender e reaprender novas maneiras. Sabemos que Odus são exercícios constantes do não saber, ou seja, de entender o conhecimento como inacabado e em construção, assim, desconstrói-se os conhecimentos cristalizados, e entende que o mesmo está em movimento, desse modo, transformam-se, encantam-se e provocam outras experiências. Os Odus são referenciais teóricos-metodológicos, são conteúdos, teorias, metodologias e instrumentos práticos que apresentam chaves de leituras e de interpretações para produção de outros olhares sobre a história e cultura a africana e afro-brasileira, sobre o pensamento afrorreferenciado, trazendo sempre deslocamentos de sentidos, a coletividade, o comunitarismo, a memória, a ancestralidade, a oralitura, o corpo, a ludicidade, o encantamento como fios condutores, pois “as ferramentas do opressor não vão derrubar a casa grande", como nos ensina Audre Lorde (1979, on-line).

Nesse movimento de existência e re-existência, escolhemos uma origem, transitamos pelos movimentos contínuos e diversos, nos desconstruímos, nos 
transformamos, pois aprendemos nas encruzilhadas da pedagogia da ancestralidade que "conhecer é reter informações, dominar técnicas e reflexões. Sabedoria é mais! Sabedoria é viver o que se conhece" (OLIVEIRA, 2007, p. 110), é ética de transformação! Assim, nos encruzilhamos com o Odu de Transformação, este que se implica no pensar/fazer desde a ética, no compartilhar, no encontro/encanto, refletir continuamente a própria ética, pois "a parte mais importante da ética é a coletividade" (OLIVEIRA apud MACHADO, 2014, p. 122). Transformar desde a ética não é qualquer transformação, é uma transformação inclusiva, em comunhão, é ancestral. A pedagogia da ancestralidade transforma, exige modos outros de pensar, refletir, criar, posicionar-se, criando metodologias outras, partindo de práticas inclusivas e tecidas por nossos corpos, pelas memórias e conhecimento de nossos saberes ancestrais, dos saberes e das histórias de nossos povos, partindo da ligação ancestral entre corpo, espiritualidade e natureza. Desse modo, Kiusam de Oliveira (2019, on-line) diz que a pedagogia da ancestralidade é o intento de "sistematizar a episteme negra em um campo teórico-metodológico em construção”, assim se faz como "um posicionamento político contrário ao que se estabeleceu no país [...], se opõe ao colonialismo e à colonialidade, que continuam reafirmando a desumanidade de negros e indígenas (Idem). É oposição, construtiva à

hegemonia epistemológica eurocentrada, propondo uma forma de ser-pesquisarconhecer-pensar-juntar-articular-agir que reconheça o continente africano como o berço da humanidade e se dá a partir da criação ou recriação de laços e formas afeto-coletivas de acolher-ouvir-aprender-falar-trocar-compartilhar, protagonizada não só pelas/os mais velhas/os, mas também pelas crianças e jovens (Idem).

É uma teoria e metodologia afrorreferenciada tecida pela ancestralidade, pelo encantamento, pela escuta sensível, pela ética do cuidado, ensinando que todas as pessoas tem algo para aprender e para ensinar, sempre. Não importa apenas o conteúdo, mas o que esse conteúdo pode fazer, as transformações que traz para o cotidiano no qual estamos inseridas, seu poder de encantamento! $\mathrm{Na}$ busca de bemviver o que conhecemos, escolhemos/encontramos nossa origem, passamos por um processo de transição e desconstruímos o que nos foi colocado de modo imposto por uma cultura que se deseja mono (cultura ocidental), transformando-nos e nos encantando, descolonizando e ampliando, trazendo diversas vozes para a construção, desconstruindo e transformando. 
Contar nossas histórias é fundante ante à necessidade de conquista da nossa humanidade que fora negada por muito tempo pelo cânone do pensamento ocidental, a necessidade de descolonização do conhecimento, assim, de nossos currículos, metodologias e didáticas. É fundante criar/usar nossas próprias categorias de análises e sistemas conceituais. Não é possível contribuir com o desenvolvimento de filosofias africanas, afrorreferenciadas, com a descolonização do conhecimento pautados na ótica epistemológica ocidental. Tal lógica nos exclui, portanto, é necessário descolonizar para nos incluirmos, para existirmos em plenitude, pois

O racismo é uma realidade violenta. Por séculos, ele tem sido fundamental para o fazer político da Europa, começando com os projetos europeus de escravização, colonização, e para a atual "Fortaleza Europa". [...] Por muitos anos, o racismo nem foi visto nem refletido como um problema teórico e prático significante nos discursos acadêmicos, resultando em um déficit teórico muito sério (Weiß, 1998). Por um lado, esse déficit enfatiza a pouca importância que tem sido dada ao fenômeno do racismo. $\mathrm{E}$, por outro lado, revela o desrespeito em relação àqueles que experienciam o racismo (KILOMBA, 2019, p. 71).

O racismo segue perpassando nosso cotidiano, a colonialidade é um projeto que atua em diferentes estruturas, assim, contar nossas histórias e nos tornarmos visíveis por nós mesmas é fundante, pois "enquanto os caçadores contarem as histórias, os leões serão sempre os vencidos" (Provérbio Africano). As histórias sobre nós não contadas por nós são perpassadas de inverdades, de uma linguagem racista, machista, excludente, não nos permitindo nos tornarmos visíveis, tendo nossos saberes roubados e reescritos por meio do olhar e do vocabulário dos brancos (KILOMBA, 2019).

Reescrever nossas histórias, implica, também em territorializar, em construir, tecermos nossos espaços e aqui nos deparamos que o Odu de Espaço que nos ensina que ele é, também, o tempo em que vivemos. É o lugar que habitamos, onde somos, onde tecemos nossos saberes, nossas experiências para construir um lugar melhor para se viver. É onde se constrói as territorialidades de um povo. O espaço, o tempo, o corpo são as tessituras da existência, "antes do tempo e do espaço há o corpo. O tempo e o espaço são corpo" (OLIVEIRA, 2009, p. 104). O espaço é o visível que habitamos e o invisível que nos habita, a "energia se dissipa no espaço (O espaço não é vazio). O espaço é um conceito mediado por signos. Ele é signo e coisa ao mesmo tempo. Os signos fazem a mediação entre as forças e as coisas (As coisas são signos). A força é signo. A forma é o invólucro do signo” (Ibid, p. 232). A sabedoria ancestral 
africana recriou seus espaços — resistências para resistir, re-existir desde sua cultura entranhada na ancestralidade que atravessou o atlântico, recriou seus espaços por meio dos terreiros de religiões de matrizes africanas, quilombos, samba, capoeira, dentre outras experiências culturais, pois a

a ancestralidade é como um tecido produzido no tear africano: na trama do tear está - horizonte do espaço; na urdidura do tecido está a verticalidade do tempo. Entrelaçando os fios do tempo e do espaço cria-se o tecido do mundo que articula a trama e a urdidura da existência (OLIVEIRA, 2009, p. 243, grifo meu).

Odu de Espaço é o território que habitamos, onde lutamos e onde somos, é físico e simbólico e tecido pelo Odu de Tempo. Esse Odu é tecido pelo Odu de Natureza, pois, na natureza tudo tem o tempo certo. Makota Valdina Pinto (2010, fonte oral), nos ensina que:

O tempo para a cultura banto, a cultura do Congo, é muito profundo, porque a formação de tudo, eles imaginam que muito tempo passou. $O$ tempo teve um tempo que não foi o nosso tempo, o tempo do humano, que é a ancestralidade. Quando a gente fala, usando a linguagem mais conhecida, que orixá é ancestral, o Inquice é ancestral, Vodun é ancestral, é porque eles vieram antes. [...] Porque a natureza veio antes do ser humano, quando surgiu o protótipo do ser humano.

O tempo é a natureza que nos tece, que nos borda. O tempo é o antes, o agora, o depois:

A gente é resultado de toda essa natureza criada antes e que a gente encontrou. $E$ esse tempo é um tempo que a gente não dá conta, a gente especula, a gente cria, as várias culturas criam histórias, se cria lendas para falar desse tempo, mas ninguém tava lá para saber, então, tudo é história, criada. Mas, é um tempo que é hoje também. Ai é que tá, que é o $x$ da questão. Esse tempo ancestral é o tempo de hoje também, se a gente vive porque a gente precisa até do vento, que é o tempo, que é tempo, não o tempo, mas que é tempo... Tempo é vento, vento é tempo. Quem é que não precisa do vento? Quem é que vive sem respirar? Ninguém... (Idem).

Não existimos fora da natureza, não somos sem o tempo. Somos espaços e potência de vida. Dona Toinha (Com-versas, 17 de Agosto de 2019, apud MACHADO, 2019), liderança do Quilombo Água Preta — CE ensinou: “Tem coisas que só o tempo para explicar. Sem palavras, mas a gente acaba entendendo”. Ela também ensina que os Odus de Tempo, Espaço (ou Território) e Natureza se entrelaçam como se fossem a mesma coisa, Dona Toinha diz: “Tempo, Território e Natureza é a mesma coisa, mas cada um tem a sua importância. É a mesma coisa? É. Mas, cada um tem a sua função” (Idem). Assim, concluímos que são Odus interdependentes, "o interessante de tudo isso é que cada um tem a sua função, no 
entanto, no final, tudo é a mesma coisa" (Idem). Os Odus nos encruzilham com as poéticas de encantamento, nos implicando com a busca de viver pautadas em uma ética do cuidado, em busca e afirmação contínua de nossa comunidade, do nosso pertencimento, da nossa origem, da nossa ancestralidade. A ética do cuidado é tecida pelo encantamento, pelo enraizamento, pela produção de conhecimento como prática de liberdade, de engajamento, de emancipação, de abertura para o diverso, inclusive o diverso que nos habita.

\section{In-conclusões Finais -Saberes Ancestrais Femininos: cabaças da existência}

Um som que ecoa em nossos ouvidos nos recordando que: é pra frente e só pra frente que iremos, pois somos o êxito da nossa linhagem. (Lorena Oliveira).

O encantamento é o canto pela vida, afirmação da vida, busca e alimento da força do viver, bem viver... O Odu de Encantamento nos ensina que só é possível pensar em justiça, emancipação e liberdade se houver vida! Por isso é fundante lutarmos por nossas vidas e é o que fazemos diariamente. O encantamento é o que nos mantém vivas, talvez seja o fio que tece a Filosofia Política Afroperspectivista que a filósofa Lorena Oliveira (2020, on-line) vem desenvolvendo, ela nos diz:

compreendo que temos conseguido nos mantermos vivxs, mesmo com todo o projeto de genocídio existente contra a população negra desse país, porque o povo preto e indígena possui uma filosofia política, que aqui conceituo como Filosofia Política Afroperspectivista, que está enraizada sobre a fortaleza de valores que não coadunam com a lógica necropolítica ocidental.

Somos cabaças da existências, tecidas por um ser-tão que habita o centro da terra, nos enraizando desde uma relação ancestral e encantada, pois "essa filosofia política está pautada na valorização / exercício da memória e da energia vital (força) que constitui tudo que há no universo" (Idem). O fazer político afroperspectivista é:

um fazer baseado na territorialidade. Um fazer que tem como referência territórios de liberdade, territórios de abundância e de solidariedade. Que não estão amparados sobre o individualismo, a propriedade, ao amor pela mercadoria e a avareza. Muito menos na desconexão com a terra e a lógica ocidental de "roubar, matar e destruir"! (OLIVEIRA, 2020, on-line). 
Lorena Oliveira em movimento com os Odus de Espaço (Territorialidade), de Tempo e Natureza tecendo nosso estar no mundo, pois

\begin{abstract}
a terra, a água, a natureza são manifestações de princípios ancestrais construtores dos seres humanos. A terra é mãe, é mulher, é generosa, é sedutora. A terra se enfeita e se aquece, se oferece para receber a chuva, sêmen que molha e deixa exalar um cheiro de vida. A terra é viva e abre suas entranhas para receber novas sementes, novas folhas, novos frutos. A terra é próspera. A terra é sagrada. Cada pedaço de terra, por menor que seja, por certo é uma síntese do mundo, uma referência de vida, assim como a água (MACHADO, 2013, p. 78, grifos meus).
\end{abstract}

O encantamento é um exercício contínuo, talvez das miudezas, de manter viva em nós as centelhas de que, apesar de tudo, podemos desconstruir, transformar, pois sermos constituídas pela ancestralidade nos coloca em constante movimento de transformAÇÃO, de construção de mundos melhores, do sagrado. É movimento do transforAMAR (MACHADO, 2019). Contar nossas histórias é estratégia, hábito de sobrevivência, modo de potencializar a vida, de resistir, de re-existir. Contar histórias é uma forma de criar, re-criar, ressignificar conceitos, movimentos próprio dos Odus! Vilma Piedade nos ensina:

...todo conceito carrega um mundo de significados e significantes... não é estático... pressupõe... Reflexão... Crítica... Discursos... Significar... Ressignificar... Multiplicidade... Transformação... Isso, tudo junto, parece funcionar como [suleadores] da questão conceitual. Logo, o conceito não é algo acabado, pronto, imutável e descolado do seu tempo. É circular. [...] O movimento é sua marca. Movimento histórico, ideológico. Movimento. Multiplicidade. Crítica (PIEDADE, 2017, p. 15-16).

É essa escrita e reescrita que faz a mediação das filosofias africanas contemporâneas. Nos mulheres filósofas das africanidades nos implicamos em uma reescrita que traga, também, as mulheres como potências criadoras, pois somos tecidas desde cosmopercepções onde o feminino carrega os princípios da criação. É necessário "ultrapassar os tiques de escrita e hábitos relativos às escolhas temáticas" (BIDIMA, 2002 apud MACHADO, 2020) que excluem as mulheres em relação "as vozes que representam os atores e as temáticas dessas filosofias”. As mulheres devem participar dessa construção, dessa re-construção, não apenas com temáticas que lhes contemplem, parece que a nós é fadado a obrigação de dizer, apenas, sobre "o que somos", "quem somos", "o que queremos", somos parte fundante da construção do mundo.

Contar outras histórias, trazer a pluralidade de nossas escrevivências implica em práxis de transformações. As filosofias africanas não estão preocupadas e não se 
dão à construção de um modelo único, são tecidas e tecem experiências práticas, plurais, enraizadas, umbilical... tecidas por tradições, ou seja, "uma espécie de psicodrama que revela à comunidade suas raízes e o corpo de valores que sustenta sua personalidade: um viático encantado para singrar o rio do tempo em direção ao reino dos ancestrais" (ZI- ZERBO, 2010, p. XXXIX). As filosofias africanas tecidas desde/ com/por saberes ancestrais femininos nos religa ao centro da terra, enraizando, encantando, maternando, cuidando!

A ancestralidade é a trilha da liberdade, liberdade de corpo inteiro! Expansão do nosso eu (coletivo) profundo em um processo contínuo de descoberta e cura das dores do mundo. Conhecimento entendido como ato de amor e este compreendido como "uma combinação de cuidado, compromisso, conhecimento, responsabilidade, respeito e confiança" (HOOKS, 2003), pois para seres encantados por sua ancestralidade "O ato de conhecer é um ato de amor, o ato de entrar e abraçar a realidade do outro, de permitir que o outro entre e abrace a nossa" (Idem). Nossas políticas de re-existências ancestrais e encantadas são tecidas por nossos corposterritórios e:

a política desde esses corpos-territórios pode ser compreendida como uma política feita com respeito à totalidade do Ser. Uma política que é alimentada/nutrida por valores civilizatórios apreendidos com a ancestralidade africana e os donos da terra, os povos pindorâmicos, que reafirmam, sopram em nossos ouvidos, diuturnamente, que a vida, a natureza/território que nos gera e nutri e o Ser só são em comunidade e não estão à venda (OLIVEIRA, 2020, on-line).

É o encantamento que pare a filosofia africana contemporânea, filosofia gestada pela ancestralidade, gestada na cabaça ancestral bordada pelos saberes ancestrais femininos, pelo feminino que nos habita. Saberes que (a)bordam nossas escrevivências, dando sentido às re-existências cotidianas. Saberes experienciados por corpos carregados de sentidos, corpos sagrados, ancestrais. Desse modo, falamos desde cosmopercepções delineadas por cosmossensações de um corpo vivo, que aprende e ensina continuamente. Conhecimento é movimento! O movimento é que proporciona a vida! De modo que as energias femininas são águas em movimentos ancestrais que permitem a existência do hoje e do amanhã. A ancestralidade guia, cuida, cura e encruzilha! O encantamento alimenta...

Os saberes ancestrais femininos propõem que nos autorizemos a contar nossas histórias, construí-las, reconstruí-las, contar sobre nossos valores, nossos 
saberes, nossas lógicas de pertencimento, de sociedade, de partilha, contar sobre nós mesmas, desde nossas escrevivências. Nossas poéticas de encantamento de resistências e re-existência tecem políticas de descolonização implicadas na potencialização da vida, de nossos corpos-territórios, são saberes que implicam no ensinar/educar/filosofar anunciando, resistindo, re-existindo, em um desafio cotidiano de descolonização, desconstruções, transformAções! Aprender a ouvir/sentir/conhecer/filosofar de corpo inteiro, desde o chão que pisamos e que nos fortalece, enraizando. O feminino é a energia uterina, a cabaça da existência... é o tempo que é vento, que é vida, é ancestralidade e encantamento!

\section{Referências}

ALVES, M. K. F. Resistência Negra no Círculo de Cultura Sociopoético: pretagogia e produção didática para a implementação da lei 10.639/03 no projovem urbano. 159f. 2015. Orientadora: Profa. Sandra Haydée Petit. Dissertação (mestrado em Educação) Universidade Federal do Ceará, Programa de Pós-Graduação em Educação, Fortaleza, 2015.

CARNEIRO, S. A construção do outro como não-ser como fundante do ser. Tese (doutorado em Educação) - Universidade de São Paulo, FEUSP, 2005.

EVARISTO, C. A escrevivência e seus subtextos. In: DUARTE, C. L.; NUNES, I. R. (Orgs.). Escrevivência: a escrita de nós: reflexões sobre a obra de Conceição Evaristo. Ilustrações Goya Lopes. 1. ed. Rio de Janeiro: Mina Comunicação e Arte, 2020.

EVARISTO, C. Destaque: Conceição Evaristo. Entrevista concedida a Ademir Pascale. Conexão Literatura, n. 24, 2017.

CHIZIANE, P. O canto dos escravizados. Belo Horizonte: Nandyala, 2018.

CHIZIANE, P. Eu, mulher... por uma nova visão de mundo. 2. ed. Belo Horizonte: Nandyala, 2016.

CHIZIANE, P. As andorinhas. Belo Horizonte: Nandyala, 2013.

DIOP, B. Soplos. In: EZE, E. C.(Org.). Pensamiento africano: cultura e sociedad. Barcelona: Ed.Bellaterra, 2005. Biblioteca de Estudios Africanos.

HOOKS, B. Ensinando a transgredir: a educação como prática de liberdade. Trad. Marcelo Brandão Cipolla. 2. ed. São Paulo: Editora WMF Martins Fontes, 2017.

HOOKS, B. De coração para coração: ensinando com amor. Heart to heart: teaching with love. In: HOOKS, B. Teaching community: a pedagogy of hope. New York: Routledge, 2003. p. 127-137. (Tradução para uso didático de Vinícius da Silva). Disponível em: https://oquartodehooks.wordpress.com/2019/02/10/de-coracao-para-coracaoensinando-com-amor/amp/?_twitter_impression=true. Acesso em: 10 fev. 2021. 
KAUR, R. o que o sol faz com as flores. Trad. Ana Guadalupe. São Paulo: Planeta do Brasil, 2018.

KILOMBA, G. Memórias da Plantação - Episódios de racismo cotidiano. Trad. Jess Oliveira. 1 ed. Rio de Janeiro: Cobogó, 2019.

KI-ZERBO, J. Introdução Geral. In: História geral da África, I: Metodologia e pré-história da África/editado por Joseph Ki-Zerbo. 2. ed. rev. Brasília: UNESCO, 2010. 992p.

LORDE, A. Mulheres Negras: As ferramentas do mestre nunca irão desmantelar a caso do mestre. Trad. Renata. In: Conferência do New Yor University Institute for the Humanities, 1979. Geledés, 10 jul. 2013. Disponível em: https://www.geledes.org.br/mulheres-negrasas-ferramentas-do-mestre-nunca-irao-desmantelar-a-casa-do-mestre/. Acesso em: 29 mar. de 2019.

MACEDO, R. S. Compreender/mediar a formação: o fundante da educação. Brasília: Liber Livro Editora, 2010.

MACHADO, A. F. Filosofia Africana Contemporânea desde os saberes ancestrais femininos: novas travessias / novos horizontes. In: Itaca - Especial Filosofia Africana, n. 36, 2020, p. 248-280. Disponível em: https://revistas.ufrj.br/index.php/Itaca/article/view/31952/19774. Acesso em: 20 de Junho de 2020.

MACHADO, A. F. Saberes Ancestrais Femininos na Filosofia Africana: Poéticas de Encantamento para Metodologias e Currículos Afrorreferenciados. 268f. 2019. Orientadora: PETIT, S. H. Tese (doutorado em Educação) — Universidade Federal do Ceará, Fortaleza, 2019.

MACHADO, A. F. Ancestralidade e Encantamento: filosofia africana mediando a história e cultura africana e afro-brasileira. 240f. 2014. Orientadora: TOURINHO, T. Dissertação (mestrado em Educação) - Universidade Federal da Bahia, Salvador, 2014.

MACHADO, V. Pele da Cor da Noite. Salvador: EDUFBA, 2013.

MARTINS, L. Performances da Oralitura: corpo, lugar da memória. Letras, n. 26, p. 63-81, nov. 2013. Disponível em: < https://periodicos.ufsm.br/letras/article/view/11881/7308>. Acesso em: 10 set. 2018.

MEIJER, R. A. S. Valorização da Cosmovisão Africana na Escola: narrativa de uma pesquisaformação com professoras piauienses. 194f. 2012. Orientadora: PETIT, S. H. Tese (doutorado em Educação). Universidade Federal do Ceará, Faculdade de Educação, Programa de Pós-graduação em Educação Brasileira, Fortaleza, 2012.

OLIVEIRA, E. D. Filosofia da ancestralidade: corpo e mito na filosofia da educação brasileira. Curitiba: Editora Gráfica Popular, 2007.

OLIVEIRA, K. R. Pedagogia da Ancestralidade. Revista eonline, 2019. Disponível em: https://www.sescsp.org.br/online/artigo/13431_PEDAGOGIA+DA+ANCESTRALID ADE. Acesso em: 08 ago. 2019.

OLIVEIRA, L. S. Filosofia Política Preta: o que zumbi e outrxs quilombista tem a nos dizer?. Le Monde Diplomatique - Brasil, edição 160, 2020. Disponível em: https://diplomatique.org.br/o-que-zumbi-e-outrxs-quilombistas-tem-a-nosdizer/?fbclid=IwAR32iE0Yu1mQ7gN3bB2x5Agle1XXKwLHmf9xul3YpEd7mWbq2awD8Z8 LJBE. Acesso em: 10 nov. 2020. 
OYĚWÙMÍ, O. Conceituando o gênero: os fundamentos eurocêntricos dos conceitos feministas e o desafio das epistemologias africanas. African Gender Scholarship: Concepts, Methodologies and Paradigms. CORDESRIA Gender Series, v. 1, p. 1-8, 2004. (Original: Conceptualizing Gender: The Eyrocentric Foundations of Feminist Concepts and the challenge of African Epistemologies, por Juliana Araújo Lopes).

PIEDADE, V. Dororidade. São Paulo: Editora Nós, 2017.

ROCHA, A. M. Oyèrónkẹ Oyěwùmí: tecituras filosóficas comprometidas com a decolonialidade. Le Monde Diplomatique - Brasil, 2020. Disponível em: https://diplomatique.org.br/oyeronke-oyewumi-tecituras-filosoficas-comprometidas-coma-decolonialidade/. Acesso em: 02 de dez. 2020.

ROCHA, A. M. A Exclusão Intelectual do Pensamento Negro. Pólemos, Brasília, v. 2, n. 4, 2014.

SOMÉ, S. O Espirito da Intimidade: ensinamentos ancestrais africanos sobre relacionamentos. São Paulo: Odysseus Editora, 2003.

\section{FONTE ORAL}

DONA TOINHA. COM-VERSAS. Entrevista realizada em Água Preta, 17 e 18 de Agosto de 2010.

PINTO, M. V. Ancestralidade. 2017. Disponível em: https://www.youtube.com/watch?v=N914diwjRbU.

PINTO, M. V. Bença, entrevista com Makota Valdina. 2010. Disponível em: https://www.youtube.com/watch?v=P0zijx0KWRE. 